\title{
The Effect of Graphene on the Protective Properties of Water-Based Epoxy Coatings on Al2024-T3
}

\author{
T. Monetta, A. Acquesta, A. Carangelo, and F. Bellucci \\ Department of Chemical Engineering, Materials and Industrial Production, University of Napoli Federico II, Piazzale Tecchio 80, \\ 80125 Napoli, Italy
}

Correspondence should be addressed to T. Monetta; monetta@unina.it

Received 14 March 2017; Revised 21 April 2017; Accepted 3 May 2017; Published 25 May 2017

Academic Editor: Flavio Deflorian

Copyright (C) 2017 T. Monetta et al. This is an open access article distributed under the Creative Commons Attribution License, which permits unrestricted use, distribution, and reproduction in any medium, provided the original work is properly cited.

0.5 and $1 \%$ wt. of graphene nanoflakes were added to an anticorrosive additives-free water-based epoxy resin applied to Al2024T3 samples. Calorimetric (DSC) and adhesion (cross-cut test) tests indicated that the presence of graphene did not affect the polymerization process of the resin or its adhesion to the substrate while it had some effect on its wettability. Electrochemical Impedance Spectroscopy (EIS) results obtained suggested that the addition of a small amount of graphene greatly enhanced the protective properties of the epoxy coating, retarding electrolytes absorption and reducing the total amount of adsorbed water. The latter occurrence suggests that the graphene effect on coating performances is related to both extended diffusion pathway length and graphene/matrix interaction due to the unique properties of graphene.

\section{Introduction}

The study of graphene effect when used as a nanofiller in polymer matrices to form advanced multifunctional materials is one of the most promising research fields in various areas of application [1-4]. Loading of graphene to polymeric materials has shown a significant increase in the electrical and thermal properties and the mechanical properties of nanocomposites [5-11]. Few papers, however, addressed the development of graphene nanocomposites with the aim of increasing the protective properties of organic coatings against corrosion phenomena [12-17]. Reports on epoxy/graphene nanocomposite coatings are less common $[14,18-20]$ and very few researchers described the use of a waterborne resin [15, 21-24]; however, the environmentally friendly solutions that take into account the new regulations about the emission of volatile organic compounds [25-28] are of considerable interest. As it is well known, several types of green surface treatments, or coating systems, have been investigated to decrease the aluminium corrosion rate when exposed to an aggressive environment [28-36]. In this study, the effect of graphene on protective properties of epoxy coating has been evaluated by incorporating reduced concentrations of nanoparticles (i.e., $0.5 \%$ and $1 \%$ by weight) into waterborne epoxy resin and applied to 2024-T3 aluminium alloys sample. The protective properties of the modified epoxy coatings were investigated by using Electrochemical Impedance Spectroscopy (EIS) and differential scanning calorimetric (DSC) techniques. Furthermore, the adhesion between the coating and the metallic substrate was evaluated by means of cross-cut test and the effect of the filler on the wettability of the coating was also addressed in this investigation.

\section{Materials and Methods}

Graphene particles, used in this work (C500, Cometox, Italy), are made of few layers with a width of less than $2 \mu \mathrm{m}$, an average thickness of about $2 \mathrm{~nm}$, and a surface area of $500 \mathrm{~m}^{2} / \mathrm{g}$, as reported by the supplier. The epoxy system (Wapex 660, Sikkens, Italy) is a commercial waterborne resin, without corrosion inhibitors. It contains, in addition to other additives (such as emulsifying and dispersing agents and surfactants) normally used in the production cycles of commercial resins, $63 \%$ wt. of solid, mainly $\mathrm{TiO}_{2}$. The volume ratio of epoxy resin to hardener used was $4: 1$ as indicated by the manufacturer. The safety data sheets for 
TABLE 1: Components of water-based epoxy resin.

\begin{tabular}{lcccc}
\hline & Common names & CAS number & \% weight & Acronym \\
\hline \multirow{2}{*}{ Component A } & Polyamine epoxy-resin adduct & $112-57-2$ & $\geq 10,<20$ & TEPA \\
& Tetraethylenepentamine & & $\geq 0.25,<1$ & DGEBA \\
& Bisphenol A-co-epichlorohydrin & $25068-38-6$ & $28064-14-4$ & DGEBF \\
\hline \multirow{3}{*}{ Component B } & Bisphenol-F epichlorohydrin & $25068-38-6$ & $250,<75$ & DGEBA \\
& Bisphenol A-co-epichlorohydrin & $28064-14-4$ & $\geq 20,<25$ & DGEBF \\
& Bisphenol-F epichlorohydrin & $26761-45-5$ & $2.5,<25$ & \\
\hline
\end{tabular}

TABLE 2: Nomenclature used to identify the different specimens.

\begin{tabular}{lc}
\hline Sample & Nomenclature \\
\hline Unfilled coating & EP \\
Coating containing $0.5 \%$ wt. of graphene & EG05 \\
Coating containing $1 \%$ wt. of graphene & EG1 \\
\hline
\end{tabular}

"component A" and "component B" of the resin report the presence of chemical compounds listed in Table 1.

The Al2024-T3 substrates, having dimensions of $20 \mathrm{~cm} \times$ $10 \mathrm{~cm} \times 0.5 \mathrm{~cm}$, were degreased by acetone and dried with air pressure before painting. In order to evaluate the influence of the dispersed graphene on the polymer matrix, specific amounts of graphene nanofiller were chosen, in particular $0.5 \%$ and $1 \%$ wt. The nomenclature adopted to individuate the samples is reported in Table 2.

The dispersion of the graphene nanoflakes in the epoxy resin has been obtained, using an ultrasonic bath with a frequency of $50 \mathrm{~Hz}$ for $20 \mathrm{~min}$, blending component $\mathrm{A}$ of the resin with graphene, by means of a hermetic box, keeping the container refrigerated. The hardener was added to the graphene/epoxy blend and mixed for another $20 \mathrm{~min}$ by using a mechanical stirrer. Finally, the hybrid coating was applied to the aluminium substrate with a spiral bar applicator. The samples were cured at $150^{\circ} \mathrm{C}$ for $10 \mathrm{~min}$. The dry thickness of the cured coatings was $27 \pm 1.3 \mu \mathrm{m}$, measured with an Elcometer Dualscope Mpor-Fp (IMCD Italia Spa, Italy).

In order to evaluate the effect of the nanofiller on the epoxy matrix properties, a thermal analysis was carried out taking $10 \mathrm{mg}$ of samples. Three scans (heating, cooling, and heating again) were carried out from 30 to $250^{\circ} \mathrm{C}$ with a heating rate of $10^{\circ} \mathrm{C} / \mathrm{min}$, for each specimen. Tests were performed in a dry nitrogen atmosphere by using a MettlerToledo DSC12E (Mettler-Toledo Spa, Italy) apparatus.

The protective properties of the coatings were investigated by EIS following ISO 16773-2016. A conventional electrochemical cell was used including a saturated calomel reference electrode (SCE), platinum as counter electrode, and the coated aluminium sample as working electrode. A frequency response analyzer (FRA), in conjunction with a potentiostat/galvanostat, 1255 and 1286 Solartron (Photo Analytical S.r.l., Italy), respectively, was employed. The electrolyte used was an air saturated $3.5 \mathrm{wt} . \% \mathrm{NaCl}$ aqueous solution and the area exposed was of about $5 \mathrm{~cm}^{2}$. Measurements were carried out at open circuit potential (OCP) over a frequency range from $10^{5}$ to $0.02 \mathrm{~Hz}$ with an amplitude sinusoidal voltage of $10 \mathrm{mV}$ up to an immersion time of 21 days.

The effect of the graphene on substrate/coating adhesion was analyzed by a Cross Hatch Cutter (Sheen Instruments, Italy), following ASTM D3359-09, whereas wettability was investigated by means of water contact angle (WCA) test using an OCA 15 EC (DataPhysics Instruments $\mathrm{GmbH}$, Filderstadt, Germany). In particular, water droplets, with a volume equal to $3,5 \mu \mathrm{L}$, were dispensed on the surface of specimens. The WCA was evaluated on an average of 50 measurements taken on different points of the surface. Finally, all measurements reported in this paper were carried out at room temperature and repeated at least three times to ensure reproducibility and accuracy.

\section{Results and Discussion}

To investigate the effect of graphene on the transition glass temperature, $T_{g}$, and hence on the physical properties of epoxy matrix, DSC measurements were carried out on the basic resin, EP, and on the epoxy-graphene coatings, EG05 and EG1. Findings obtained were reported in Figure 1. As can be seen from this figure, both the residual cure and $T_{g}$ (at about $100^{\circ} \mathrm{C}$ ) were not affected by the graphene content. These results suggest that the presence of a small amount of graphene does not affect either the glass transition temperature or the curing of the epoxy matrix. Therefore, the effect of the low amount of graphene on the protective behavior of the coating, as will be discussed in the subsequent paragraph, must not be attributed to a physical modification of the matrix of the epoxy or to a different curing process.

Good adhesion between the coating and the substrate is a "desideratum" property. In fact, it is well known that water molecules at the metal/coating interface may decrease the coating adhesion accelerating the corrosion of the metallic substrate [37]. Thus, poor adhesion permits aggressive ions to accumulate at the coating/metal interface and to trigger a degradation process. Cross-cut adhesion tests (Figure 2) highlighted that the loading of graphene nanoflakes had no effect on the coating/substrate adhesion. In fact, no peelings were observed in any of the coatings, receiving $4 \mathrm{~B}$ rating (less than $5 \%$ peeling) according to the ASTM standard.

In order to study the influence of graphene on the wettability of the coating, water contact angle measurements were carried out (Figure 3 ). 


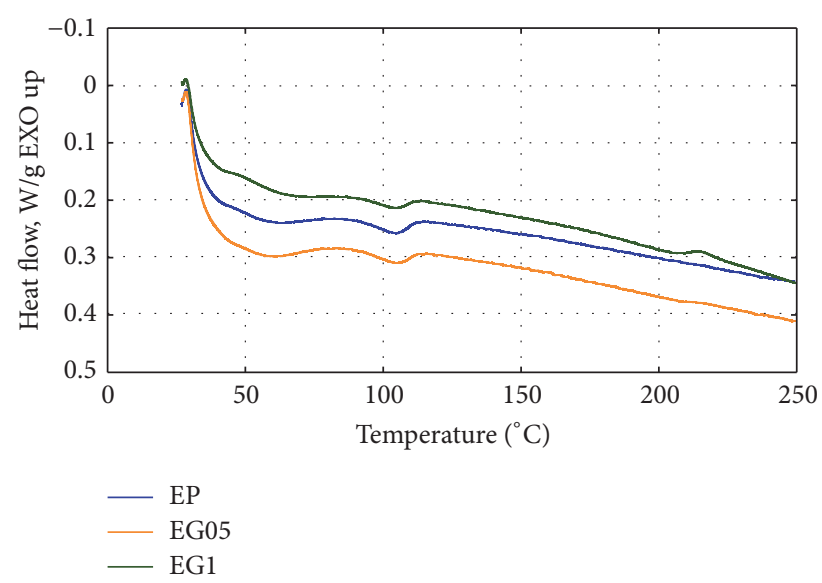

FIGURE 1: DSC thermograms of the unfilled coating (EP) and the epoxy-graphene coating containing $0.5 \%$ wt. (EG05) or $1 \%$ wt. (EG1) of the nanofiller.

TABLE 3: Water contact angle average values of all tested specimens.

\begin{tabular}{lccc}
\hline Sample & EP & EG05 & EG1 \\
\hline Water contact angle (degree) & $65,1 \pm 0,5$ & $71,3 \pm 0,8$ & $81,2 \pm 0,9$ \\
\hline
\end{tabular}

The measured water contact angle (see Table 3 ) of the unfilled epoxy coating is about $65,1^{\circ}$; when the filler is dispersed in the epoxy resin, the contact angle increased to $71.3^{\circ}$ (EG05 sample) and 81,2 (EG1 sample). This rise is linked to the amount of nanoflakes loaded (i.e., by increasing the filler content, an increase of the contact angle is observed). Thus, graphene nanoflakes confer some hydrophobic character to the epoxy resin contributing to the reduction of the amount of water uptake.

EIS measurements were performed in order to investigate the effect of graphene addition on the coatings' performance, when exposed to an aerated $3.5 \% \mathrm{wt}$. $\mathrm{NaCl}$ aqueous solution up to 21 days. Findings obtained are presented as Bode and phase angle plots in Figures 4, 5, and 6.

The impedance modulus trend of the EP sample, shown in Figure 4(a), indicates poor corrosion protection offered by the no-loaded epoxy coating. In fact, after only one day of exposure to the test solution, the impedance modulus at low frequency (attributed to the coating resistance) is slightly less than $10^{7} \Omega \cdot \mathrm{cm}^{2}$. The latter value is generally regarded as the lower limit beyond which the protective properties of coatings are considered poor. This result shows the limited protective properties of the coating due to the absence of anticorrosive pigments as well as to the water and the electrolytes that penetrate rapidly into the coating. After 4 days of immersion, the impedance modulus at low frequency has shifted to the value of about $4 \times 10^{6} \Omega \mathrm{cm}^{2}$, while it was possible to detect a new phenomenon that is developing at the substrate/metallic interface, namely, the initiation of a corrosion process. This effect becomes even more evident with exposure time and is attributed to the absorption of water and electrolytes by the coating with the development of local anodic area at the metallic substrates [38]. For prolonged immersion time (14-21 days), a new phenomenon is displayed, characterized by an increase of the impedance at low frequency (see data at 21 days) that is currently attributed to the formation of corrosion products at the interface filling the pores of the coating [36].

The latter impedance data were confirmed by the phase angle plot that better emphasizes these effects [38]. Thus, looking at data shown in Figure 4(b), it is possible to observe that the phase angle plot, after one day of exposure to the test solution, exhibits a value of about 80 degrees at high frequency, while a minimum value ( 3 degrees) is observed at a frequency of about $0.25 \mathrm{~Hz}$. Moreover, the increase of the phase angle observed in the lowest frequency range $\left(10^{-2}-10^{0} \mathrm{~Hz}\right)$ suggests the initiation of the corrosion process at the alloy/coating interface. Therefore, it can be assumed that after $24 \mathrm{~h}$ of exposure the solution has penetrated the coating, reaching the metallic substrate where corrosion phenomena started to develop [38]. The subsequent shift of the phase angle at high frequency, as a function of immersion time, is also consistent with further degradation of the coating, while the wide variation of the phase angle observed in the medium-high frequency range suggests a pronounced effect of corrosion products on the coating structure.

Data obtained by the EG05 specimen, shown in Figure 5, exhibit a quite different behavior compared to the unfilled sample. The impedance modulus decreases slowly with time (Figure 5(a)), suggesting a better stability of the loaded epoxy coating. Namely, the impedance modulus displays a little bit higher value after one day of immersion compared to that exhibited by the unloaded epoxy, suggesting better protective properties of the coating. For further immersion in the test solution up to 21 days, a slight decrease of the impedance modulus is continuously observed. It is worth mentioning that no increase in the impedance modulus is detected in the time interval of 14-21 days, as it was reported for the base coating, EP. Therefore, the addition of $0.5 \%$ wt. of graphene improves the EIS response of the epoxy loaded coating.

The phase angle data, shown in Figure 5(b), further support the beneficial effect of graphene on the stability of the epoxy filled coating. Thus, looking at the data shown in this figure, it is possible to observe that the phase angle plot, after one day of exposure, exhibits a value of about 80 degrees at high frequency, while the minimum value is observed at a frequency of about $0.1 \mathrm{~Hz}$. Moreover, the increase of the phase angle observed in the lowest frequency range $\left(10^{-2}-10^{-1} \mathrm{~Hz}\right)$ is much less pronounced when compared with the data obtained for base coating, suggesting that the initiation of the corrosion process at the alloy/coating interface involves restricted metallic area [38]. Furthermore, it is also worth mentioning the shift of the phase angle versus the low frequency range in the time interval of 7-14 days. These findings can be attributed to the corrosion products at the interface filling the coating porosity, leading to a more effective and compact coating [37,38]. Finally, in the time interval of 14-21 days, the degradation of the coating clearly appears as suggested by the shift at high frequency of the phase angle plot. Data reported in Figure 5(b) also support the idea that the filled epoxy appears quite stable as a function of the immersion time in the test solution even if 


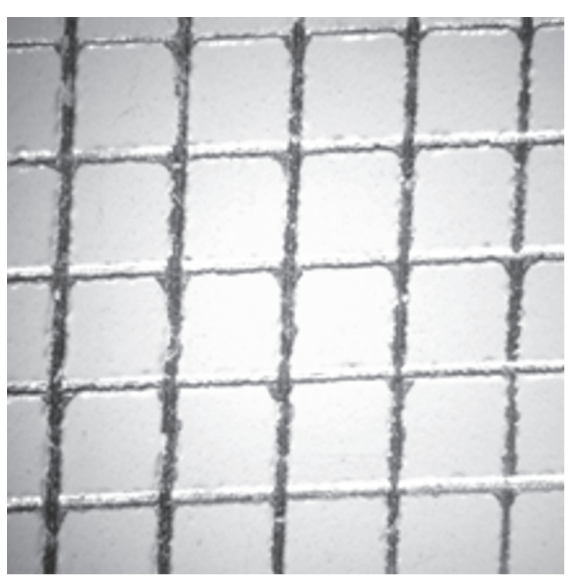

(a)
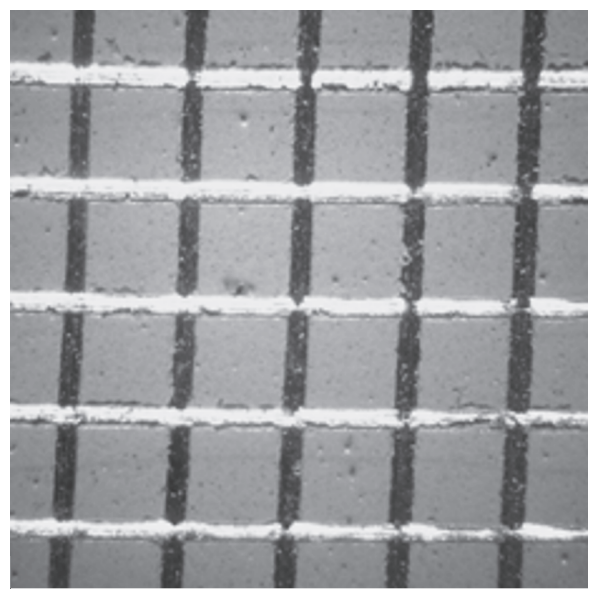

(c)

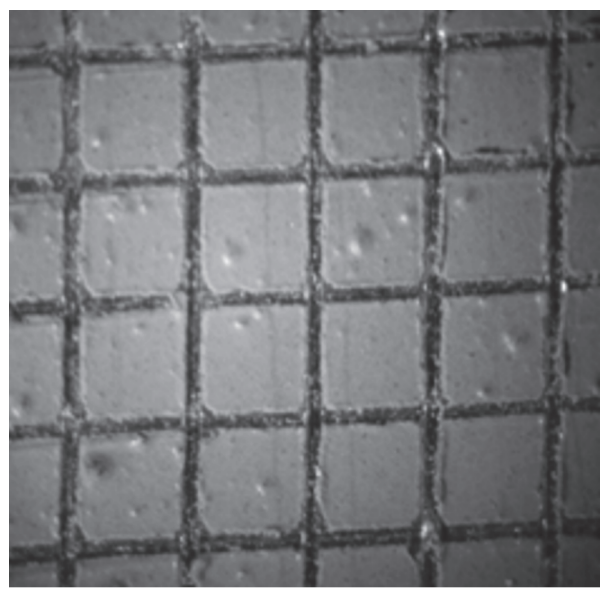

(e)

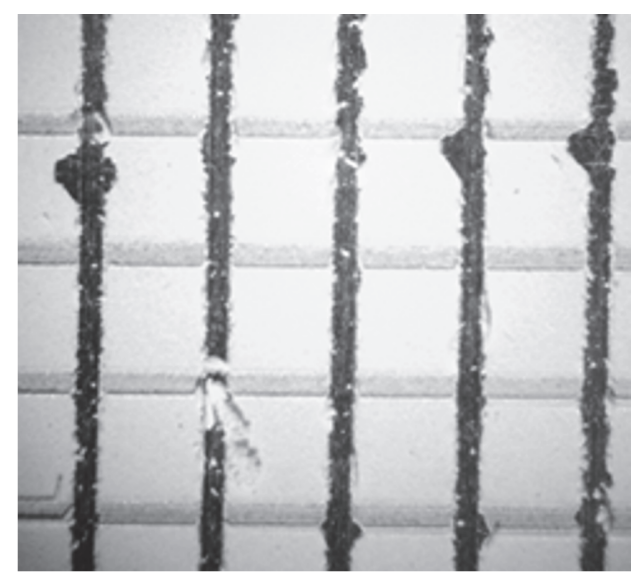

(b)

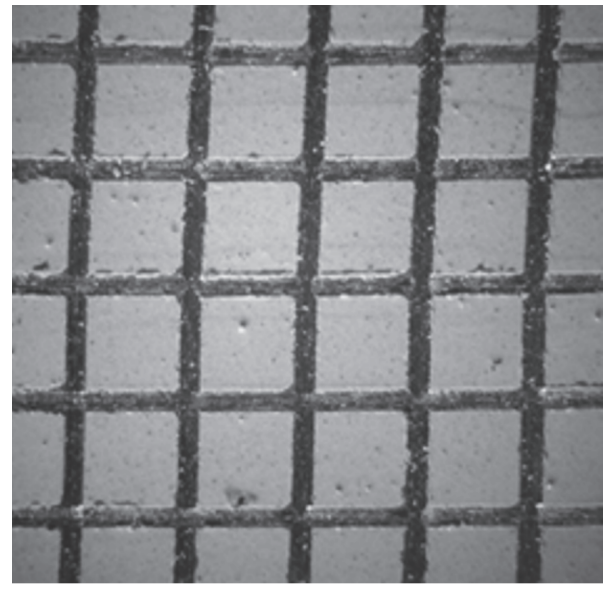

(d)

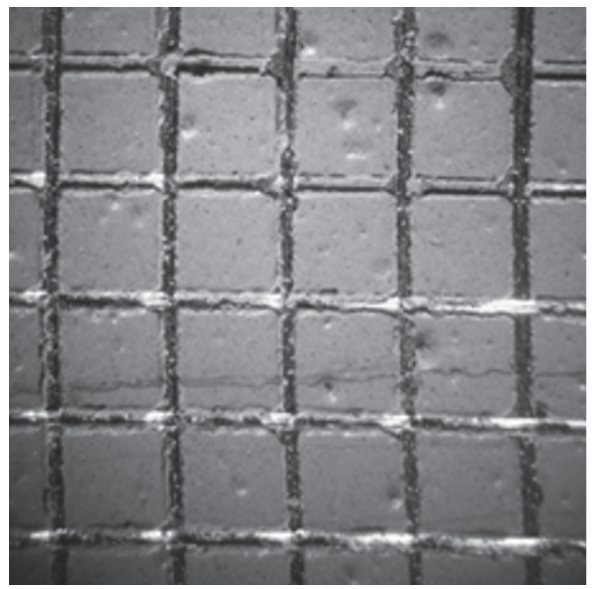

(f)

FIGURE 2: Cross-cut test on the EP sample (a) before and (b) after the test, on the EG05 sample (c) before and (d) after the test, and on the EG1 sample (e) before and (f) after the test.

the coating was fully penetrated by the electrolyte at one day of immersion.

The impedance modulus of the EG1 sample (Figure 6(a)) showed the highest impedance value (about $6 \times 10^{7} \Omega \mathrm{cm}^{2}$ ), as a function of the immersion time, further suggesting the beneficial effect of the addition of $1 \%$ graphene to the epoxy matrix as far as the protective properties of this coating are concerned.

An overview of the phase angle plot (Figure 6(b)) reveals further beneficial effects due to the addition of graphene to 


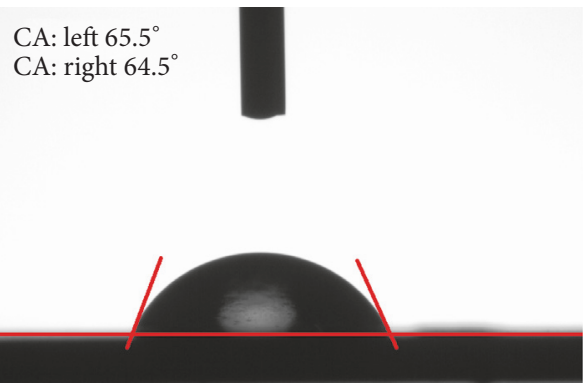

(a)
CA: left $71.6^{\circ}$

CA: right $72.1^{\circ}$

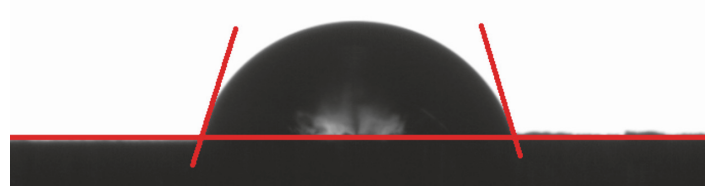

(b)

CA: left $81.6^{\circ}$

CA: right $80.6^{\circ}$

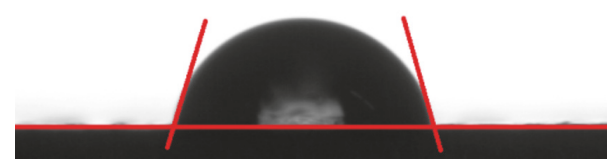

(c)

FIGURE 3: Water contact angle pictures of (a) EP, (b) EG05, and (c) EG1 coatings.

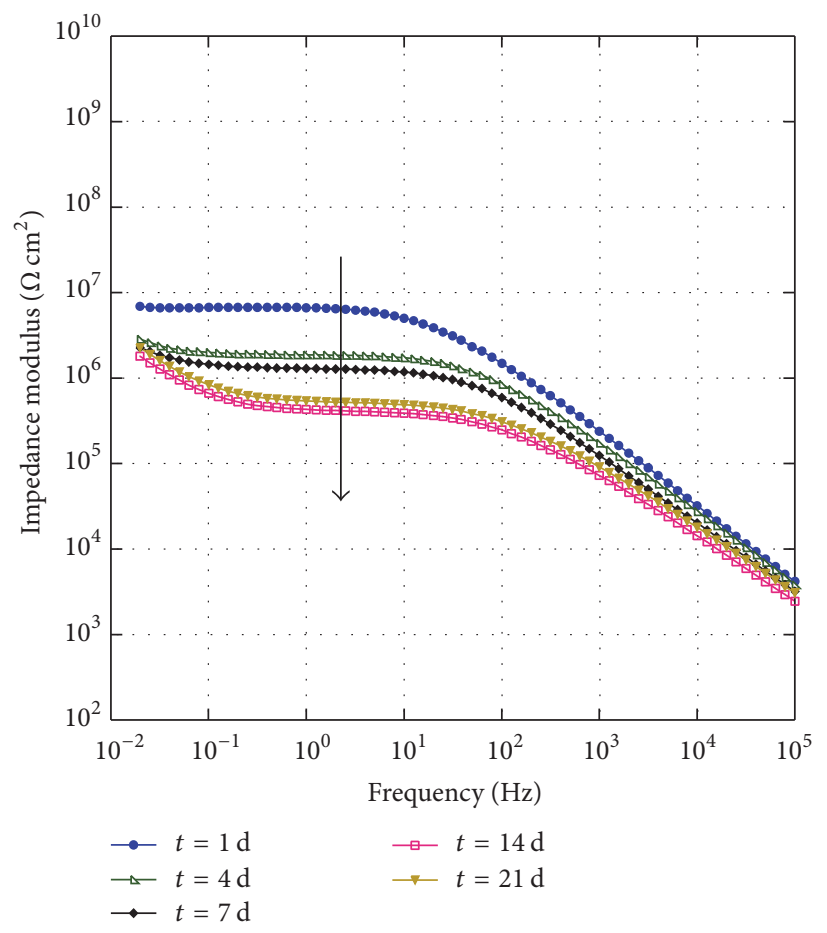

(a)

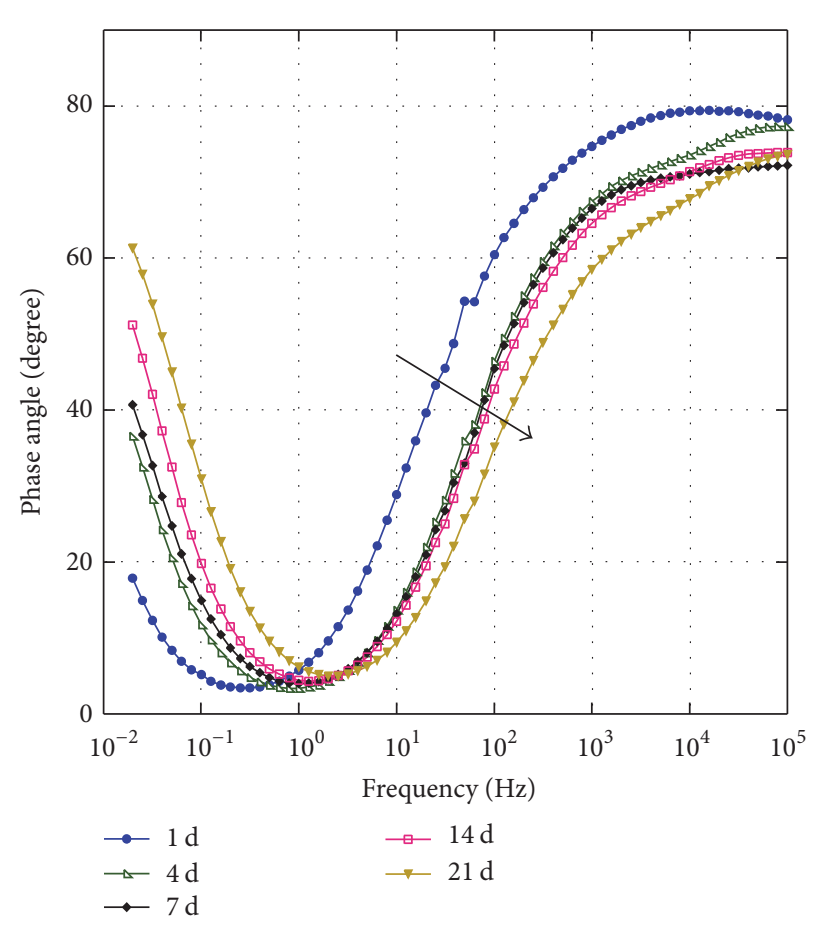

(b)

FIGURE 4: (a) Impedance modulus and (b) phase angle plots of the unfilled coating (EP) in 3.5\% wt. NaCl aqueous solution. 


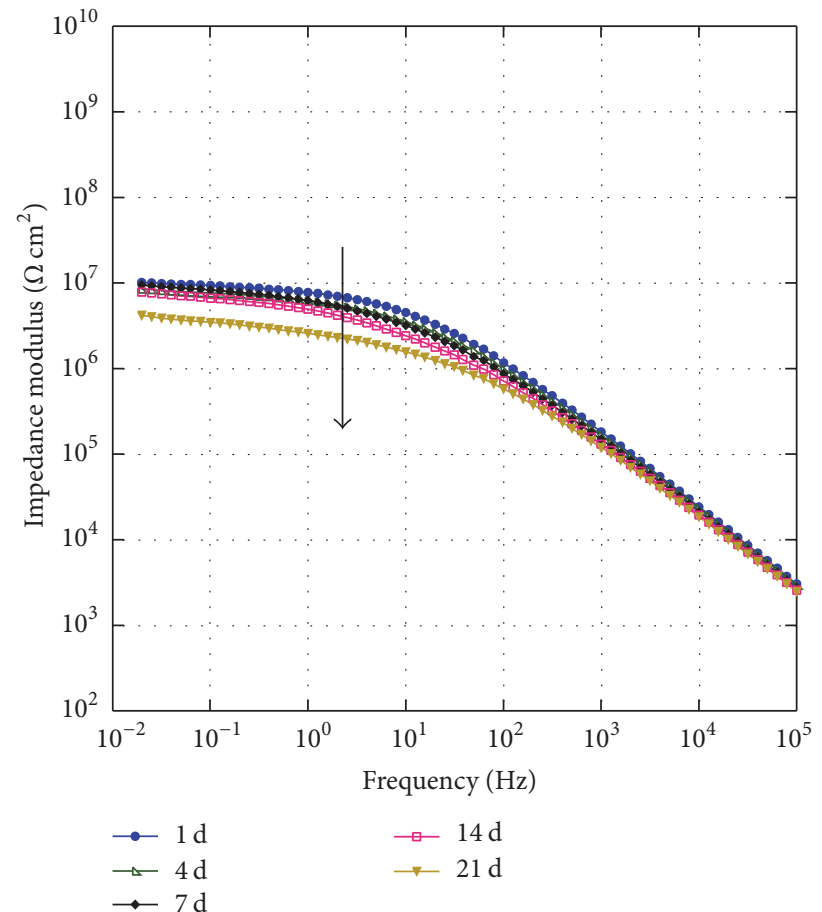

(a)

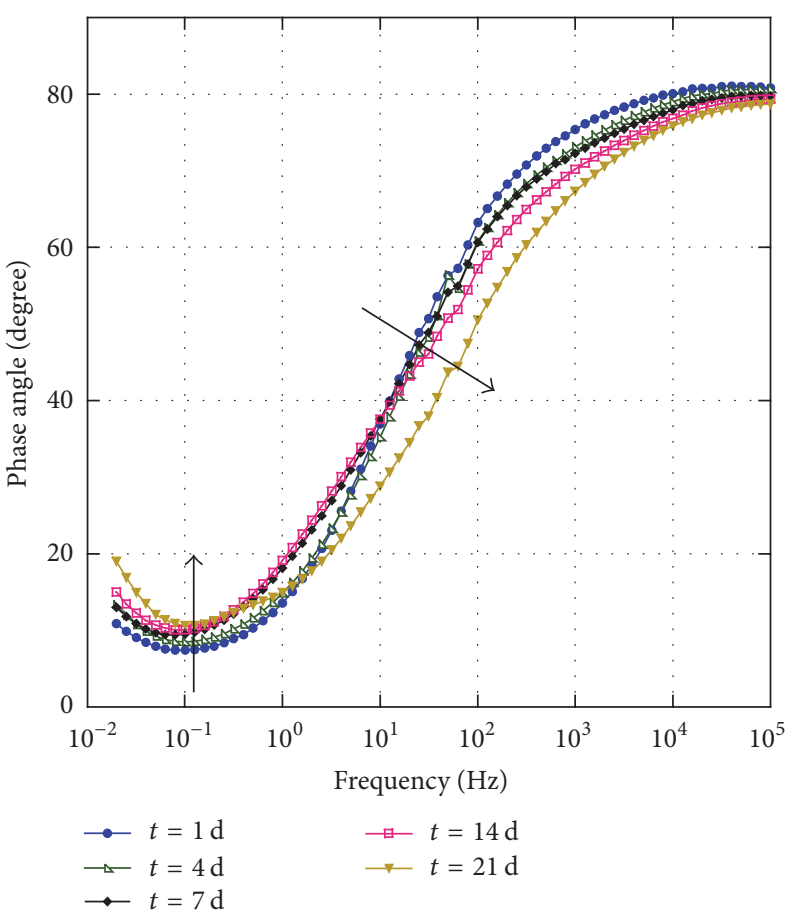

(b)

FIGURE 5: (a) Impedance modulus and (b) phase angle plots of epoxy-graphene coating loaded with 0.5\% wt. (EG05) of graphene nanofiller in a $3.5 \%$ wt. $\mathrm{NaCl}$ aqueous solution.

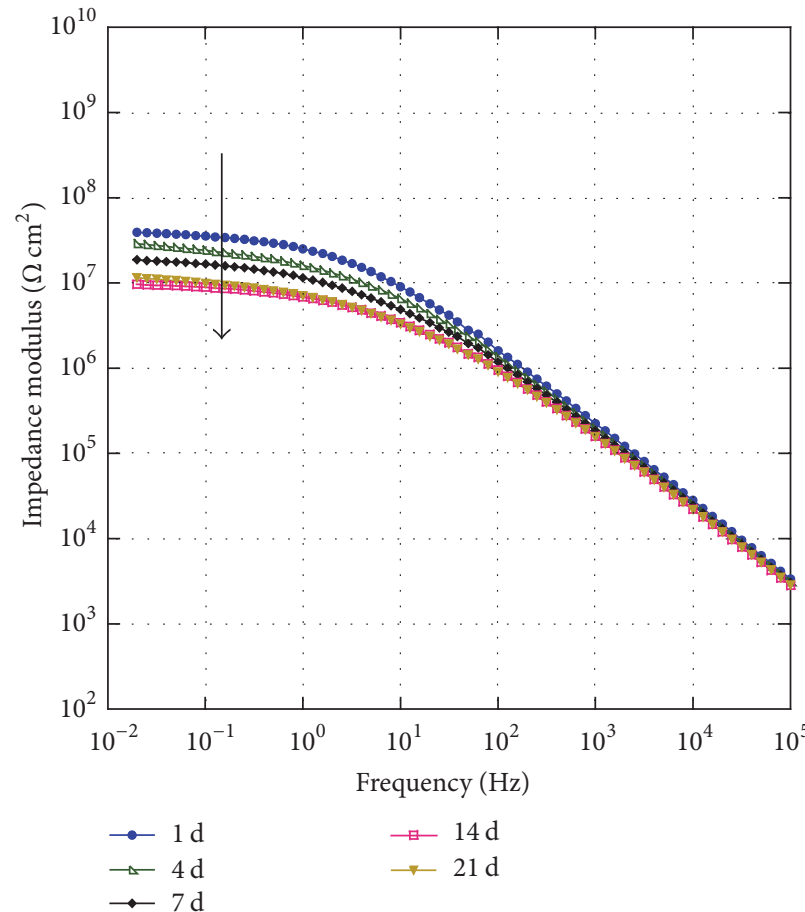

(a)

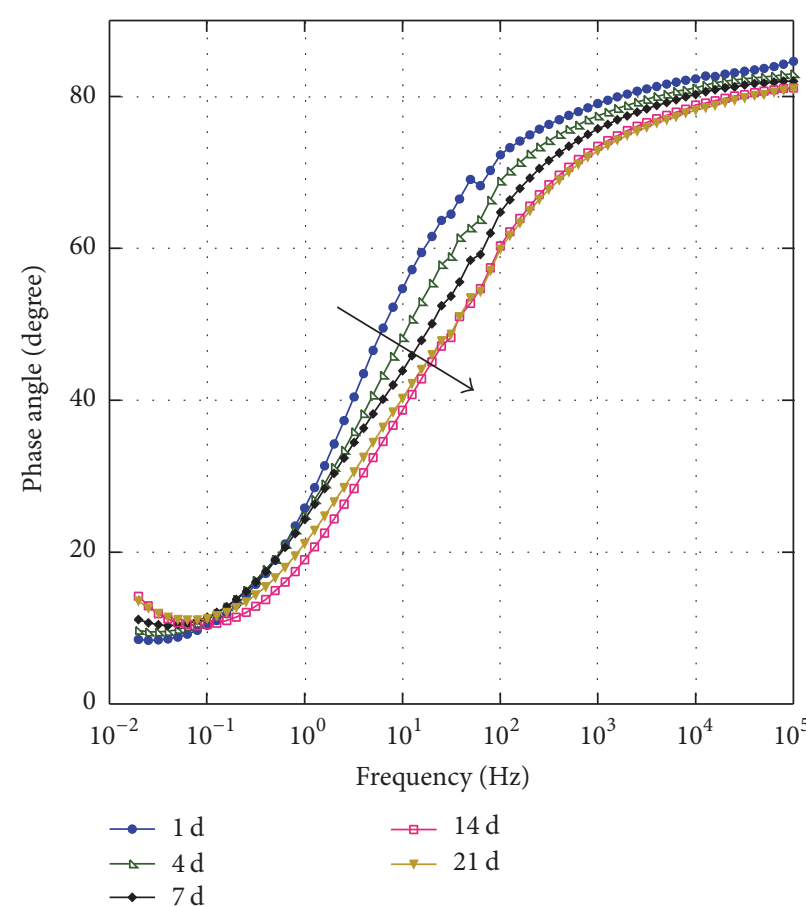

(b)

FIGURE 6: (a) Impedance modulus and (b) phase angle plots of epoxy-graphene coating loaded with 1\% wt. (EG1) of graphene nanofiller in a $3.5 \%$ wt. $\mathrm{NaCl}$ aqueous solution. 


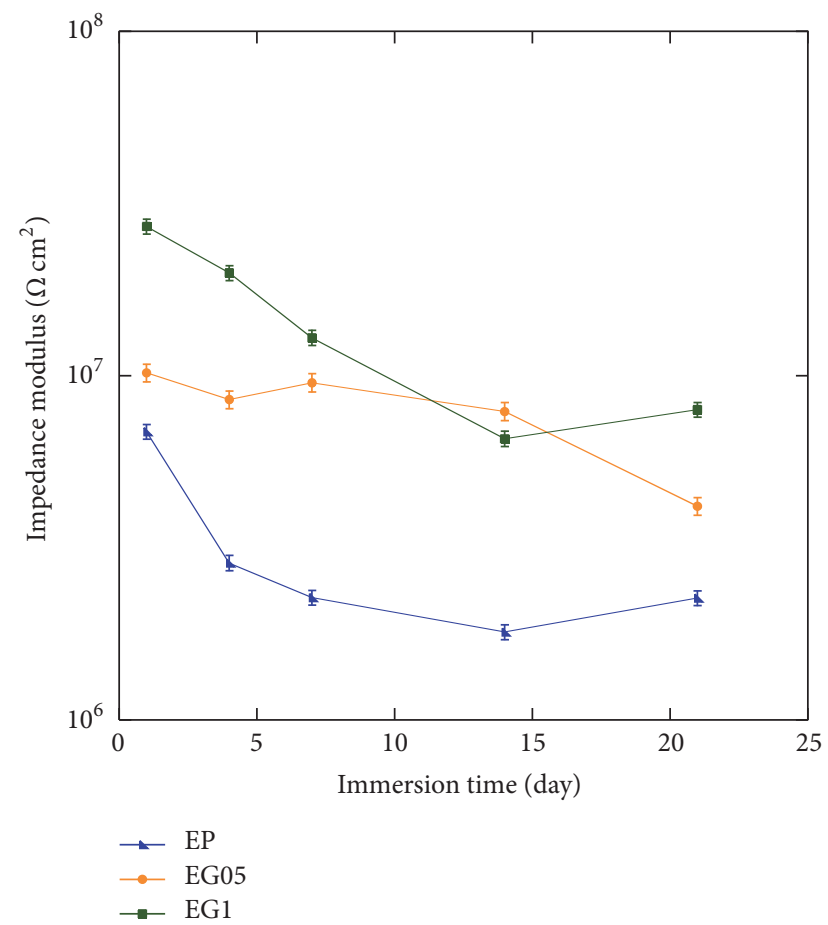

FIGURE 7: Impedance modulus values of unfilled coating (EP) and coating filled with $0.5 \% \mathrm{wt}$. and $1 \% \mathrm{wt}$. of graphene nanofiller (EG05 and EG1, resp.) at $0.02 \mathrm{~Hz}$.

the base epoxy as reported in the following. Data at very low frequency upon 4 days of immersion do not clearly show a minimum as observed in the base and $0.5 \%$ wt. filled epoxy coating. Therefore, no full penetration of the electrolyte occurs in the above time interval, suggesting a compact behavior of the filled epoxy at least for the first 4 days. A slight tendency to increase in the phase angle appears in the time interval of 4-7 days of exposure, while a clear minimum is observed after 14 days, suggesting the initiation of the corrosion process at the metallic interface. In addition, all phase angle data as a function of the immersion time are shifted to the low frequency, suggesting better protective properties as far as the addition of graphene nanofillers is concerned.

Meaningful impedance data related to the effect of graphene on the protective properties of the epoxy coating evaluated at $0.02 \mathrm{~Hz}$ are reported in Figure 7. As can be seen from this figure, the filled nanocoatings exhibited impedance modulus greater than the unfilled base epoxy for all exposure times showing the noticeable effect due to the use of graphene. In addition, EGl showed an impedance modulus of one order of magnitude greater than that exhibited by the base epoxy for all exposure times.

Further insight into the beneficial effect of graphene on the protective properties of the base epoxy can be obtained by the knowledge of water transport since water permeation is closely related to the metallic substrate corrosion rate. The permeation of water in a coating is usually determined by the

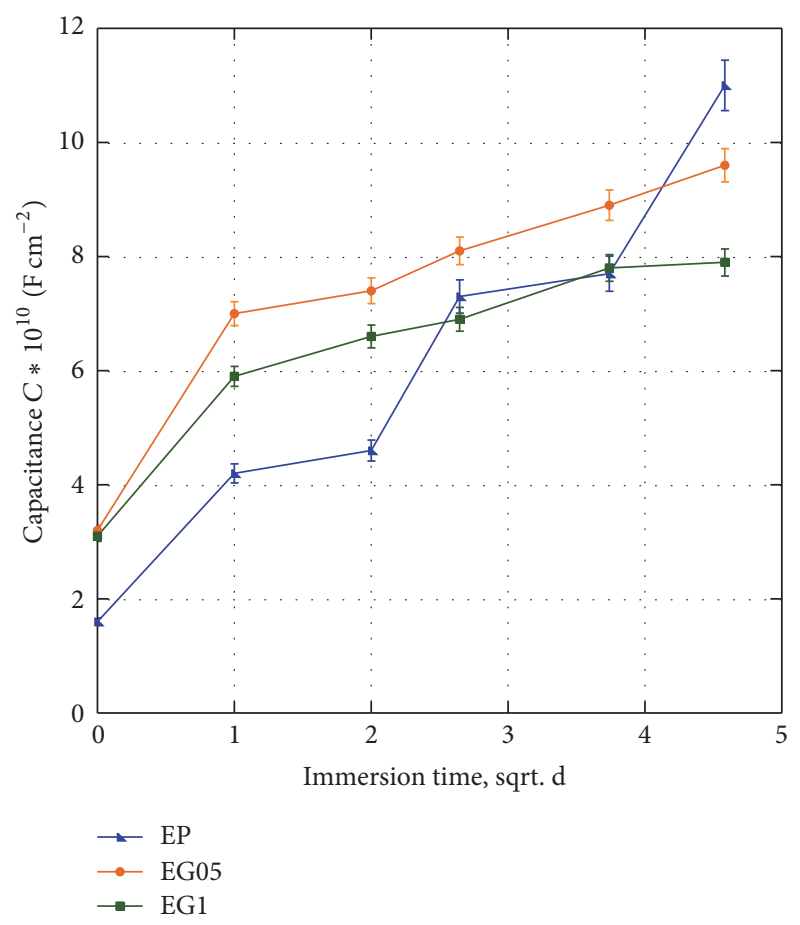

FIGURE 8: Coating capacitance for unfilled coating (EP) and coating filled with $0.5 \%$ wt. (EG05) and 1\% wt. (EG1) of graphene resins.

increase of the capacitance of the paint film as a function of the exposure time $[39,40]$.

Capacitance values can be obtained by the impedance data by using the following equation [41]:

$$
C=\frac{1}{\left(2 \pi f_{i} Z_{i}\right)}=\frac{1}{\left(2 \pi f Z^{\prime \prime}\right)},
$$

where $f_{i}$ (equal to $6.5 \mathrm{kHz}$ ) is a frequency value where the slope of the impedance modulus curve is equal to -1 and $Z_{i}$ is the imaginary part (or reactive component) of the impedance. Findings obtained are reported in Figure 8 as a function of the square root of $t$.

As can be seen from this figure, all investigated coatings show an increase of the capacitance with exposure time that is currently attributed to the uptake of water. However, Figure 8 shows also a different shape of transient highlighting a different mechanism of water adsorption and transport into the nanocoatings. Namely, the base coating capacitance exhibits a step-like increase in the time interval of 1-16 days, whereas a smooth-like behavior is shown only by the $0.5 \%$ wt. filled epoxy in the time interval of 1-4 days. Quite different is the behavior of the $1 \%$ wt. nanofilled epoxy; in fact, no step-like increase was observed in this case and an almost steady state is shown at a later stage of immersion, suggesting a quasi-Fickian behavior. By using the theory of diffusion modified for an applied film to a metallic substrate [40], the water diffusion coefficient through the coating is proportional to the initial slope of the capacitance curve when it is plotted versus the square root of the time, $t$. Inspection of data reported in Figure 8 reveals that the slope of EG1 is 
lower than those exhibited by the base and the EG05. This finding suggests that the addition of $1 \% \mathrm{wt}$. of graphene to the base epoxy modifies both the mechanism of water uptake and water diffusivity, thus reducing the accumulation of water at the metallic interface. Furthermore, from the values of capacitance extrapolated at time zero, the relative permittivity of the coatings can be obtained. These values are 4.93, 10.21, and $9.70 \mathrm{~F} / \mathrm{cm}^{2}$ for the base and for the 0.5 and $1 \%$ filled coatings, respectively. These values are in agreement with literature data for an epoxy resin [42] and with the effect of "carbon" filler on the relative permittivity of polymeric materials that is attributed to the polarizing effect of graphene [42]. Data reported above are in agreement with literature data suggesting that the increased performances of organic coatings are attributed to the barrier effect played by graphene that induces a water diffusivity decrease through the coating $[43,44]$. In other words, the effect of graphene seems to be due, simply, to an increase of pathway length of water through the coating, acting as other nanoparticles used as a filler. Data reported in Figure 8 show that the change in capacitance of the epoxy coating assumes a step-like behavior, displaying a sharp increase at the beginning of the test, followed by a quasi-steady-state plateau and a subsequent step rise. However, nanocomposite coatings, after the first 4 days of immersion, show a slight increase, day by day, to the end of immersion time, reaching a steady value, indicating a different water absorption process. Data reported in this paper suggest that the observed behavior of the nanofilled epoxy can be attributed to a different mechanism of water adsorption and transport through the coating rather than to a simple barrier effect. This assumption has not been highlighted until now and needs to be verified by collecting more data.

\section{Conclusions}

In this work, the properties of graphene loaded water-based epoxy coating, when applied to Al2024-T3 sample, were evaluated. Data obtained in this investigation showed that the structural properties and the adhesion to the metallic substrate were not affected by the presence of graphene, while nanoflakes addition led to a slight increase of the hydrophobic character of the coating. Furthermore, EIS data collected in this paper showed that loaded coatings exhibit improved performances toward corrosion protection of the metallic substrate. This behavior was attributed both to a barrier and to a different mechanism of water transport through the filled epoxy coating.

\section{Conflicts of Interest}

The authors declare that there are no conflicts of interest regarding the publication of this paper.

\section{References}

[1] S. Kumar, S. Raj, S. Jain, and K. Chatterjee, "Multifunctional biodegradable polymer nanocomposite incorporating graphene-silver hybrid for biomedical applications," Materials \& Design, vol. 108, pp. 319-332, 2016.

[2] R. B. Ladani, S. Wu, A. J. Kinloch et al., "Multifunctional properties of epoxy nanocomposites reinforced by aligned nanoscale carbon," Materials \& Design, vol. 94, pp. 554-564, 2016.

[3] C. Wang, Y. Lan, W. Yu, X. Li, Y. Qian, and H. Liu, "Preparation of amino-functionalized graphene oxide/polyimide composite films with improved mechanical, thermal and hydrophobic properties," Applied Surface Science, vol. 362, pp. 11-19, 2016.

[4] S. Zhao, H. Chang, S. Chen, J. Cui, and Y. Yan, "Highperformance and multifunctional epoxy composites filled with epoxide-functionalized graphene," European Polymer Journal, vol. 84, pp. 300-312, 2016.

[5] H. Kim, Y. Miura, and C. W. Macosko, "Graphene/polyurethane nanocomposites for improved gas barrier and electrical conductivity," Chemistry of Materials, vol. 22, no. 11, pp. 3441-3450, 2010.

[6] S. H. Song, K. H. Park, B. H. Kim et al., "Enhanced thermal conductivity of epoxy-graphene composites by using nonoxidized graphene flakes with non-covalent functionalization," Advanced Materials, vol. 25, no. 5, pp. 732-737, 2013.

[7] B. Tang, G. Hu, H. Gao, and L. Hai, "Application of graphene as filler to improve thermal transport property of epoxy resin for thermal interface materials," International Journal of Heat and Mass Transfer, vol. 85, pp. 420-429, 2015.

[8] Y. Wang, J. Yu, W. Dai et al., "Enhanced thermal and electrical properties of epoxy composites reinforced with graphene nanoplatelets," Polymer Composites, vol. 36, no. 3, pp. 556-565, 2015.

[9] A. S. Wajid, H. S. T. Ahmed, S. Das, F. Irin, A. F. Jankowski, and M. J. Green, "High-performance pristine graphene/epoxy composites with enhanced mechanical and electrical properties," Macromolecular Materials and Engineering, vol. 298, no. 3, pp. 339-347, 2013.

[10] F. Wang, L. T. Drzal, Y. Qin, and Z. Huang, "Mechanical properties and thermal conductivity of graphene nanoplatelet/epoxy composites," Journal of Materials Science, vol. 50, no. 3, pp. 10821093, 2015.

[11] B. Zhang, R. Asmatulu, S. A. Soltani, L. N. Le, and S. S. A. Kumar, "Mechanical and thermal properties of hierarchical composites enhanced by pristine graphene and graphene oxide nanoinclusions," Journal of Applied Polymer Science, vol. 131, no. 19, Article ID 40826, 2014.

[12] K.-C. Chang, M.-H. Hsu, H.-I. Lu et al., "Room-temperature cured hydrophobic epoxy/graphene composites as corrosion inhibitor for cold-rolled steel," Carbon, vol. 66, pp. 144-153, 2014.

[13] K.-C. Chang, W.-F. Ji, M.-C. Lai et al., "Synergistic effects of hydrophobicity and gas barrier properties on the anticorrosion property of PMMA nanocomposite coatings embedded with graphene nanosheets," Polymer Chemistry, vol. 5, no. 3, pp. 1049-1056, 2014

[14] D. Liu, W. Zhao, S. Liu, Q. Cen, and Q. Xue, "Comparative tribological and corrosion resistance properties of epoxy composite coatings reinforced with functionalized fullerene C60 and graphene," Surface and Coatings Technology, vol. 286, pp. 354-364, 2016.

[15] S. Liu, L. Gu, H. Zhao, J. Chen, and H. Yu, "Corrosion resistance of graphene-reinforced waterborne epoxy coatings," Journal of Materials Science \& Technology, vol. 32, no. 5, pp. 425-431, 2016.

[16] M. Rajabi, G. R. Rashed, and D. Zaarei, "Assessment of graphene oxide/epoxy nanocomposite as corrosion resistance coating on 
carbon steel," Corrosion Engineering Science and Technology, vol. 50, no. 7, pp. 509-516, 2015.

[17] B. Ramezanzadeh, S. Niroumandrad, A. Ahmadi, M. Mahdavian, and M. H. M. Moghadam, "Enhancement of barrier and corrosion protection performance of an epoxy coating through wet transfer of amino functionalized graphene oxide," Corrosion Science, vol. 103, pp. 283-304, 2016.

[18] B. Ramezanzadeh, A. Ahmadi, and M. Mahdavian, "Enhancement of the corrosion protection performance and cathodic delamination resistance of epoxy coating through treatment of steel substrate by a novel nanometric sol-gel based silane composite film filled with functionalized graphene oxide nanosheets," Corrosion Science, vol. 109, pp. 182-205, 2016.

[19] Z. Yu, H. Di, Y. Ma et al., "Preparation of graphene oxide modified by titanium dioxide to enhance the anti-corrosion performance of epoxy coatings," Surface and Coatings Technology, vol. 276, pp. 471-478, 2015.

[20] Z. Yu, L. Lv, Y. Ma, H. Di, and Y. He, "Covalent modification of graphene oxide by metronidazole for reinforced anti-corrosion properties of epoxy coatings," RSC Advances, vol. 6, no. 22, pp. 18217-18226, 2016.

[21] L. Gu, S. Liu, H. Zhao, and H. Yu, "Facile preparation of water-dispersible graphene sheets stabilized by carboxylated oligoanilines and their anticorrosion coatings," ACS Applied Materials \& Interfaces, vol. 7, no. 32, pp. 17641-17648, 2015.

[22] W. Xiao, Y. Liu, and S. Guo, "Composites of graphene oxide and epoxy resin assuming a uniform $3 \mathrm{D}$ graphene oxide network structure," RSC Advances, vol. 6, no. 90, pp. 86904-86908, 2016.

[23] N. Yousefi, X. Lin, Q. Zheng et al., "Simultaneous in situ reduction, self-alignment and covalent bonding in graphene oxide/epoxy composites," Carbon, vol. 59, pp. 406-417, 2013.

[24] T. Monetta, A. Acquesta, and F. Bellucci, "Graphene/epoxy coating as multifunctional material for aircraft structures," Aerospace, vol. 2, no. 3, pp. 423-434, 2015.

[25] "Council Directive 1999/13/EC of 11 March 1999 on the limitation of emissions of volatile organic compounds due to the use of organic solvents in certain activities and installations," Official Journal of the European Union, no. L 085, pp. 0001-0022, 1999.

[26] F. Andreatta, M. Bortolotto, A. Lanzutti, L. Paussa, D. Bravin, and L. Fedrizzi, "Environmentally friendly conversion coating for aluminium alloy AA6014," in Proceedings of 18th International Corrosion Congress, pp. 355-366, November 2011.

[27] F. Deflorian, S. Rossi, and M. Fedel, "Aluminium components for marine applications protected against corrosion by organic coating cycles with low environmental impact," Corrosion Engineering Science and Technology, vol. 46, no. 3, pp. 237-244, 2011.

[28] C. Sinagra, F. Bravaccino, C. Bitondo et al., "Green Technology for Surface Treatments of Aluminium Foil for Flexible Packaging," Key Engineering Materials, vol. 710, pp. 186-191, 2016.

[29] C. Bitondo, A. Bossio, T. Monetta, M. Curioni, and F. Bellucci, "The effect of annealing on the corrosion behaviour of 444 stainless steel for drinking water applications," Corrosion Science, vol. 87, pp. 6-10, 2014.

[30] A. Carangelo, M. Curioni, A. Acquesta, T. Monetta, and F. Bellucci, "Cerium-based sealing of anodic films on AA2024T3: effect of pore morphology on anticorrosion performance," Journal of the Electrochemical Society, vol. 163, no. 14, pp. C907C916, 2016.

[31] T. Monetta, A. Acquesta, V. Maresca et al., "Characterization of aluminum alloys environmentally friendly surface treatments for aircraft and aerospace industry," Surface and Interface Analysis, vol. 45, no. 10, pp. 1522-1529, 2013.

[32] A. Scala, A. Squillace, T. Monetta, D. B. Mittonb, D. Larsonb, and F. Belluccia, "Corrosion fatigue on 2024T3 and 6056T4 aluminum alloys," Surface and Interface Analysis, vol. 42, no. 4, pp. 194-198, 2010.

[33] J. Carneiro, J. Tedim, S. C. M. Fernandes et al., "Chitosan-based self-healing protective coatings doped with cerium nitrate for corrosion protection of aluminum alloy 2024," Progress in Organic Coatings, vol. 75, no. 1-2, pp. 8-13, 2012.

[34] H. A. Fetouh, T. M. Abdel-Fattah, and M. S. El-Tantawy, "Novel plant extracts as green corrosion inhibitors for 7075-t6 aluminium alloy in an aqueous medium," International Journal of Electrochemical Science, vol. 9, no. 3, pp. 1565-1582, 2014.

[35] M. Gobara, H. Kamel, R. Akid, and A. Baraka, "Corrosion behaviour of AA2024 coated with an acid-soluble collagen/hybrid silica sol-gel matrix," Progress in Organic Coatings, vol. 89, pp. 57-66, 2015.

[36] T. Monetta, D. B. Mitton, and F. Bellucci, "Protective properties of organic coatings on plasma-treated cold rolled aluminum," Electrochemical and Solid-State Letters, vol. 7, no. 11, pp. B39B41, 2004.

[37] L. De Rosa, T. Monetta, and F. Bellucci, "Moisture uptake in organic coatings monitored with EIS," Materials Science Forum, vol. 289-292, no. 1, pp. 315-326, 1998.

[38] F. Mansfeld, "Use of electrochemical impedance spectroscopy for the study of corrosion protection by polymer coatings," Journal of Applied Electrochemistry, vol. 25, no. 3, pp. 187-202, 1995.

[39] F. Bellucci and L. Nicodemo, "Water transport in organic coatings," Corrosion, vol. 49, no. 3, pp. 235-247, 1993.

[40] L. Nicodemo, F. Bellucci, A. Marcone, and T. Monetta, "Water and oxygen transport as performance parameters of paint films," Journal of Membrane Science, vol. 52, no. 3, pp. 393-403, 1990.

[41] G. W. Walter, "A review of impedance plot methods used for corrosion performance analysis of painted metals," Corrosion Science, vol. 26, no. 9, pp. 681-703, 1986.

[42] C. C. Ku and R. Liepins, Electrical Properties of Polymers: Chemical Principles, Hanser Publishers, 1987.

[43] Y. Su, V. G. Kravets, S. L. Wong, J. Waters, A. K. Geim, and R. R. Nair, "Impermeable barrier films and protective coatings based on reduced graphene oxide," Nature Communications, vol. 5, article 4843, 2014.

[44] B. M. Yoo, H. J. Shin, H. W. Yoon, and H. B. Park, "Graphene and graphene oxide and their uses in barrier polymers," Journal of Applied Polymer Science, vol. 131, no. 1, Article ID 39628, 2014. 

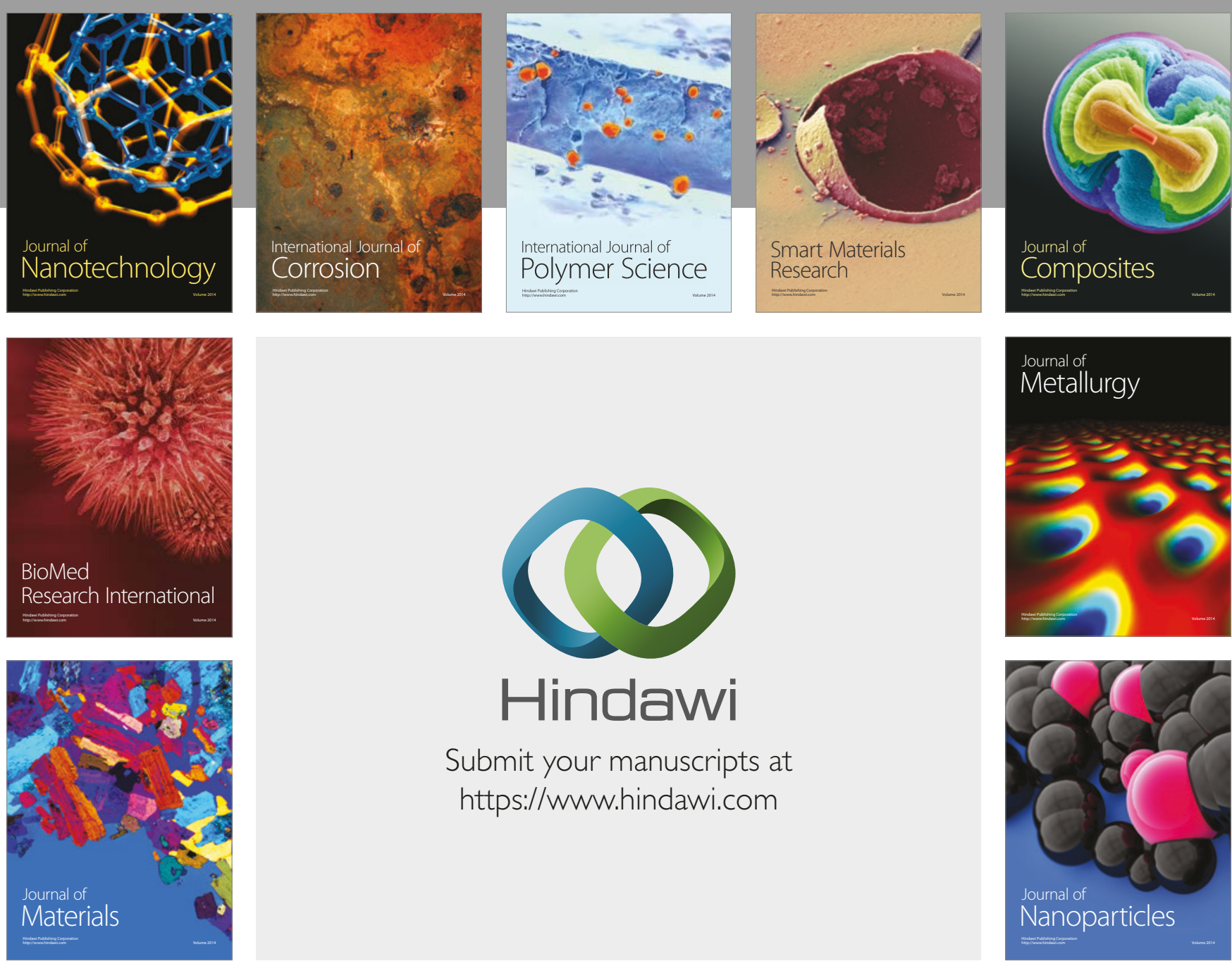

\section{Hindawi}

Submit your manuscripts at

https://www.hindawi.com
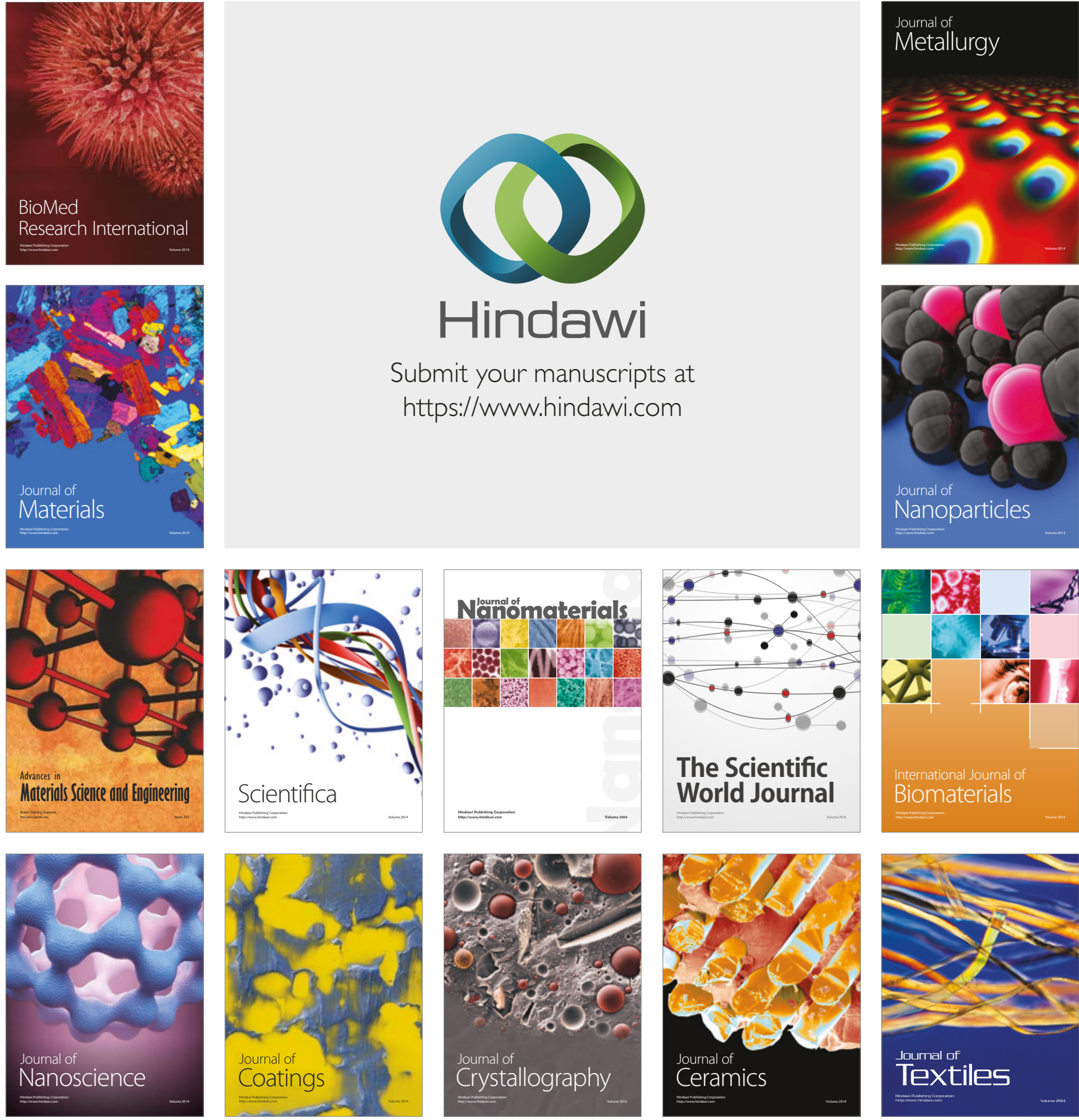

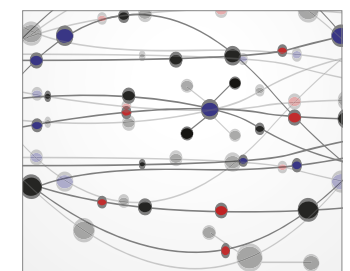

The Scientific World Journal
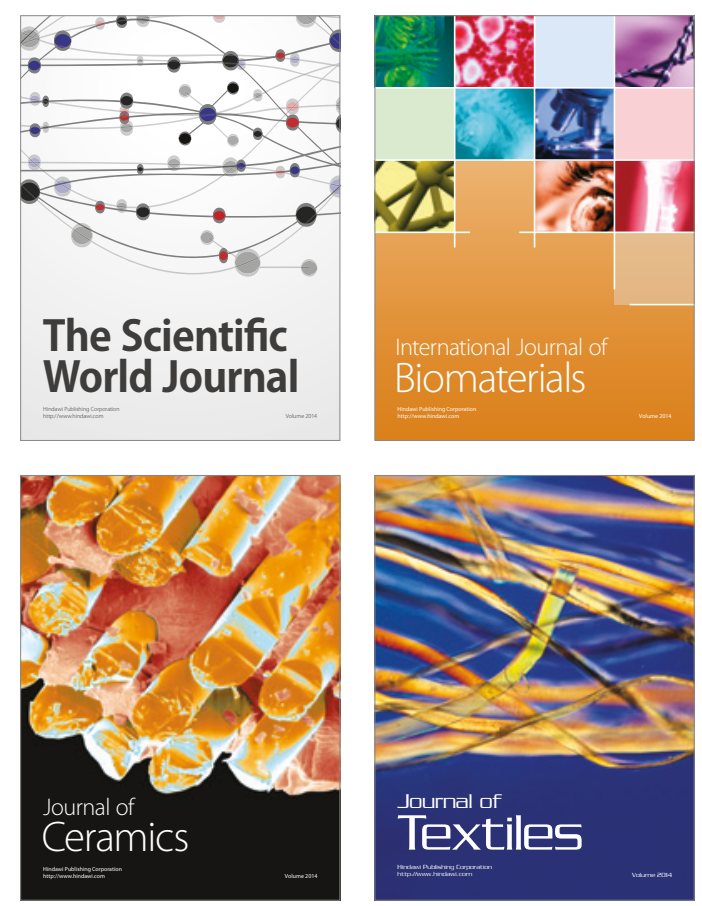